\title{
Proposição de Novos Valores de Referência PaRa InSPEÇÃo de VÉ́́culos OTTO
}

\author{
Gabriel Murgel Branco ${ }^{1}$, Fábio Cardinale Branco ${ }^{1}$, Alfred Szwarc ${ }^{2}$, José Mauro Napoleone ${ }^{3}$, \\ Marcos Brandão ${ }^{3}$ \\ ${ }^{1}$ EnvironMentality - Tecnologia com Conceitos Ambientais \\ ${ }^{2}$ ADS Engenharia e Consultoria \\ ${ }^{3}$ Controlar S.A.
}

\begin{abstract}
E-mails: gabriel.tcl@uol.com.br, fabio.tcl@uol.com.br, alfred.ads@terra.com.br, napoleone@terra.com.br, marcos_brandao_brasil@yahoo.com
\end{abstract}

\section{RESUMO}

A análise estatística das emissões medidas por meio do Programa de Inspeção e Manutenção de Veículos em Uso na cidade de São Paulo - I/M-SP, que funcionou de 2008 a 2013, demonstra que os Valores de Referência utilizados para a verificação da conformidade dos veículos são, na maioria dos casos, apropriados para os dois primeiros anos de funcionamento de qualquer Programa de I/M no país, eliminando os problemas mais comuns que provocam aumento significativo das emissões, criando o hábito da manutenção preventiva e melhorando a qualidade dos serviços da rede reparadora.

A existência de histogramas bi-modais identifica a ocorrência de problemas frequentes alheios à fabricação e não controlados adequadamente pelos Programas I/M. A análise dos percentis superiores das distribuições dos resultados obtidos pelos veículos "aprovados" permitiu o estabelecimento de critérios e uma metodologia para a revisão dos Valores de Referência a serem aplicados em uma etapa mais avançada do Programa, visando reduzir a ocorrência desnecessária de emissões muito acima do que é possível obter na maioria dos veículos de cada ano-modelo.

A partir do terceiro ano de operação do Programa I/M, entretanto, tais valores podem e devem ser reduzidos progressivamente, buscando atingir os níveis de emissão que os veículos são efetivamente capazes de atender com manutenção adequada. Como consequência, a efetividade do Programa pode ser fortemente ampliada, elevando a qualidade da manutenção preventiva sem a introdução de métodos de ensaio sofisticados e mais caros.

\section{INTRODUÇÃO}

A Resolução CONAMA 18/1986, que implantou o PROCONVE, previu o desenvolvimento de Programas de Inspeção e Manutenção dos veículos em circulação para assegurar que " $a$ população os mantenha em conformidade com as suas especificações originais e coíba as adulterações e modificações de projeto dos sistemas que interfiram nas emissões de poluentes" $^{\text {"[1] }}$. Visando estes objetivos básicos, a Resolução CONAMA 418/2009 estabeleceu procedimentos simples, expeditos e de baixo custo para a verificação de conformidade, a periodicidade anual para a inspeção e valores de referência (VRs) a serem utilizados como 
limites máximos admissíveis nesse procedimento, cujos padrões se mostram adequados para o início do Programa.

As estatísticas dos resultados da inspeção veicular ambiental permitem a identificação dos Valores Característicos (VC) de emissão de cada ano e modelo, conforme definido no artigo "Valores característicos dos parâmetros de referência de emissões dos veículos brasileiros [2]", apresentado no XXI SIMEA, em 2013. Os VCs são inferiores aos VRs, indicam o estado de manutenção possível de ser obtido no veículo considerado, e podem apontar a necessidade de sua manutenção preventiva. A partir do conhecimento desses valores, é possível verificar se os VRs, conforme definição de Branco et alii estabelecida no seu capítulo 3 - Procedimentos de avaliação e o significado técnico do ensaio de emissões para $I / M^{[3]}$, a serem utilizados como limites para a reprovação de um veículo em Programas de Inspeção e Manutenção I/M, possuem tolerância suficiente para detectar a existência de desvios graves de manutenção sem imporem reprovações desnecessárias.

As médias e os percentis $90 \%, 95 \%$ e $98 \%$ das emissões corrigidas de CO e $\mathrm{HC}$ em marcha lenta, dos veículos aprovados em Programas I/M, caracterizam bem a eficácia do Programa, isto é, a qualidade efetiva do setor de reparação de veículos e o comportamento das frotas na vida real. A análise criteriosa desses parâmetros é uma ferramenta importante para indicar a necessidade de ajuste dos VRs adotados na inspeção dos veículos do ciclo Otto, posto que, em alguns casos, estes valores são significativamente menores do que o valor máximo definido pelo CONAMA para a aprovação dos veículos na regulamentação atual. Estas folgas decorrem da fixação dos VRs com base em estatísticas preliminares obtidas dos primeiros estudos sobre o assunto, anteriores à implantação do Programa I/M na cidade de São Paulo, o que gerou VR permissivos em muitos casos.

No ano de implantação de um Programa I/M em uma nova região, enquanto a população local ainda não tiver adquirido o hábito de efetuar a manutenção preventiva de seus veículos, com vistas ao controle de emissões, e a rede de manutenção ainda não esteja em plenas condições para tal, VRs preliminares e mais lenientes devem ser aplicados, de forma a não produzir um número excessivo de reprovações, o que geraria reações contrárias da sociedade e poderia inviabilizar todo o Programa. É oportuno registrar que Programas I/M bem estruturados e operados $^{[4]}$ apresentam percentuais globais de reprovação da ordem de $20 \%$.

No caso do Programa I/M-SP, após ultrapassado o período inicial de aprendizado dos proprietários de veículos e da rede de reparação, e de haver sido obtido um número bastante representativo de resultados das inspeções, torna-se possível a adoção de VRs ajustados à realidade da frota em uso, que varia com o tempo, permitindo ajustar estes valores e, consequentemente, aumentar a eficiência do Programa, aproximando a frota dos níveis de emissão que representem uma manutenção ideal, como recomendado no manual do proprietário dos veículos. O estabelecimento de uma metodologia segura para a revisão dos VRs do Programa I/M, baseada em dados efetivamente observados, constitui a base para um aprimoramento da regulamentação do CONAMA, que pode ser implantado em qualquer região quando as estatísticas locais indicarem a sua viabilidade, geralmente após o segundo ano de operação do Programa I/M.

Como estas análises levam a VRs mais severos e determinados estatisticamente isentos de tolerâncias, os erros de medição também devem ser considerados para evitar falsas reprovações decorrentes das tolerâncias características dos equipamentos de medição de gases utilizados. Os limites atuais do CONAMA já incluem tais tolerâncias que, por isso, não são mencionadas explicitamente. Este trabalho propõe uma nova abordagem para o tema, a ser considerada pelos órgãos ambientais, apresentando em separado os valores de referência e os 
erros máximos inerentes às medições. Esta abordagem está em consonância com os princípios expressos na regulamentação do INMETRO, porém, esta também precisa ser revista frente à necessidade de tolerâncias menores que as atualmente permitidas, como prescreve a Organização Internacional de Metrologia Legal - OIML.

Uma vez que existe uma variedade grande de combinações entre combustíveis e tecnologias de veículos do ciclo Otto, o detalhamento de cada caso não caberia neste trabalho, de forma que será dada maior ênfase à metodologia com base nos exemplos mais notáveis ou representativos para, ao final, serem apresentados os Valores de Referência propostos para todos os casos.

\section{Embasamento teórico e metodologia}

Em processos produtivos, quanto menos eficiente for o sistema de controle da qualidade, maior será a variabilidade apresentada nos resultados. No caso do Programa I/M, quanto menor for o controle efetuado sobre o estado de manutenção da frota, maior será a dispersão dos valores de emissão. A realidade é que a cultura da manutenção preventiva ainda é limitada em nosso país, sendo mais efetiva no período de garantia do veículo. Passado esse período, grande parte da frota faz manutenção preventiva apenas de um número limitado de itens, frequentemente realizados de forma insuficiente (com menor frequência do que a especificada ou em oficinas não qualificadas), e uma outra parte estará sujeita apenas a manutenções corretivas quando o veículo apresentar defeitos muito evidentes que afetam sua utilização de forma visível. Também é preciso considerar que uma parcela da população adultera intencionalmente seus veículos através da retirada do conversor catalítico, alteração do chip de controle eletrônico etc., visando possíveis aumentos de potência, alteração do combustível ou outras modificações que colocam o veículo em desconformidade com a tecnologia original de fábrica.

Cada tipo de alteração ou de defeito do veículo produzirá um aumento característico nas emissões de cada modelo de veículo. Consequentemente, o histograma dos valores medidos na primeira inspeção anual no Programa I/M apresentará ao menos dois comportamentos distintos: um para os veículos bem mantidos, cuja variabilidade é consequência da variação natural da produção, desgaste natural dos veículos, temperatura ambiente e qualidade do combustível utilizado; e outro para os veículos mal mantidos ou adulterados, para os quais a variabilidade é decorrente de defeitos de manutenção, mau funcionamento ou quebra/ausência de componentes e de diversos tipos de adulterações.

Nos primeiros anos de funcionamento de um Programa I/M, o VR utilizado para a aprovação dos veículos é naturalmente mais tolerante, permitindo a aprovação de veículos com problemas de manutenção que afetam as emissões de forma limitada. Mas, à medida que o Programa I/M evolui no tempo e os problemas principais dos veículos vão sendo corrigidos, como resultado do processo de inserção da inspeção na vida cotidiana e do aprendizado da rede de reparação, torna-se possível a aplicação de VRs mais restritivos, visando levar todos os usuários a efetuar a correta manutenção dos seus veículos. Esse processo promove a melhoria contínua da qualidade da manutenção dos veículos da frota alvo do I/M. Todavia, para que tenham sucesso, estas revisões devem ser conduzidas com cuidado para que as reprovações não sejam exageradamente elevadas, tomando por base as características da frota circulante na região, o poder econômico dos proprietários de veículos e a capacitação da rede de reparação local. Obviamente, ao se implantar um Programa I/M em uma dada região é fundamental desenvolver, em paralelo, medidas de capacitação dessa rede e de oferta de peças e componentes de reposição de qualidade, como vem sendo realizado em São Paulo. 
A figura 1.1 ilustra um comportamento teórico de resultados de emissão da frota pertencente a um mesmo nível tecnológico.

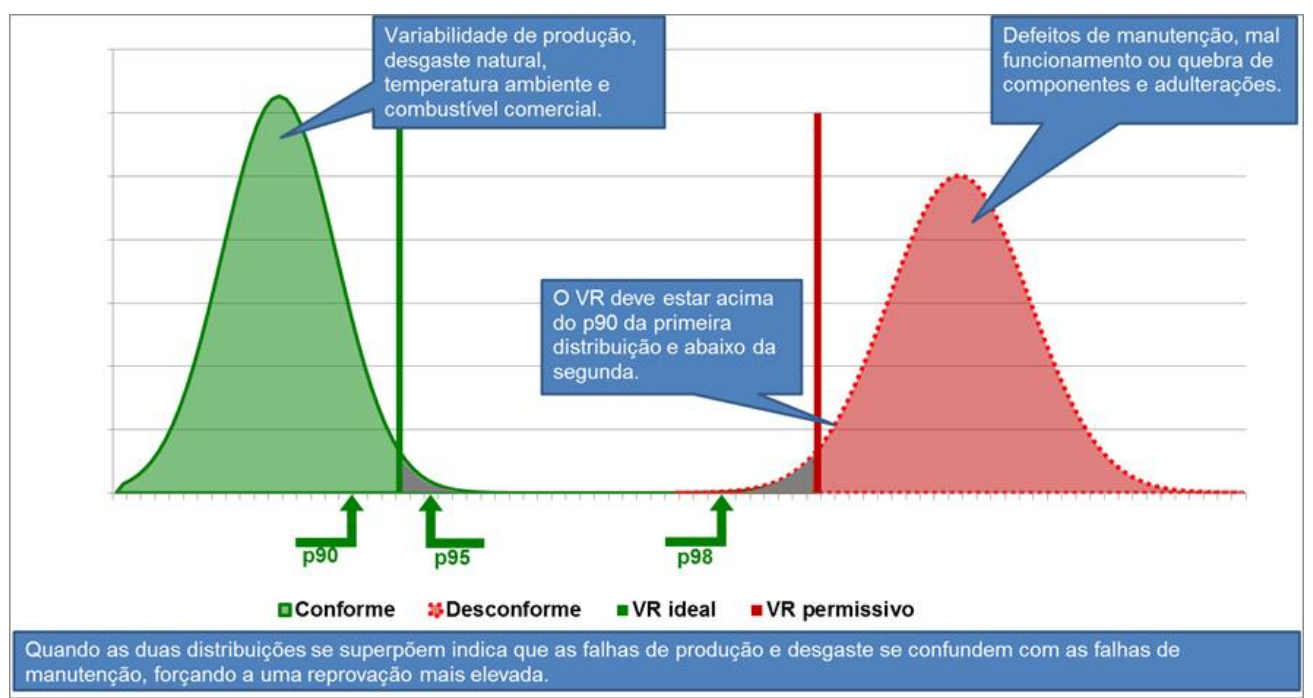

Figura 1.1 - Exemplo de mistura de duas distribuições representando as emissões de veículos bem mantidos e aqueles com manutenção deficiente

Um método seguro para determinar qual o VR ideal que segregue apenas os veículos bem mantidos deve se basear necessariamente nos parâmetros estatísticos dos veículos aprovados, posto que estes são os mais representativos das características originais dos veículos envolvidos, associadas ao desgaste natural previsto no seu projeto, uma vez que não é possível segregar apenas os veículos que efetuaram a manutenção conforme recomendado pela fábrica e em oficinas qualificadas. Por esses motivos, as análises feitas sempre envolvem uma parcela de veículos que apresentam defeitos de manutenção com pequena influência sobre as emissões, representada pelo intervalo entre as áreas das duas distribuições na figura 1.1. No exemplo dado, os percentis indicados pelas setas (p90 a p98) referem-se apenas à distribuição dos valores de veículos aprovados (distribuição à esquerda).

Para verificar se o VR está adequado à frota de uma determinada tecnologia e idade, deve-se verificar primeiramente as distâncias entre o percentil de 98\% (p98) e o VR em questão, bem como entre o p98 e o p95. Caso estes distanciamentos sejam muito elevados, isso significa que a distribuição dos veículos bem mantidos não está sendo efetivamente controlada, como mostrado no exemplo. Quanto mais efetivo for o controle efetuado com base no VR, mais próximas estarão as duas distribuições e, consequentemente, o VR será aproximado do p98, bem como o p98 aproximado do p95, sem a assimetria observada em distribuições anômalas.

Como indicado neste exemplo hipotético, o VR muito permissivo faz com que a distribuição dos veículos aprovados seja contaminada por veículos que apresentam falhas de manutenção (falsos positivos). Assim, deve-se buscar um valor que exclua esses casos, sem provocar uma elevação exagerada das reprovações e nem causar reprovações indevidas (falsos negativos).

No exemplo apresentado, a distribuição percentílica dos valores atende à curva apresentada na figura 1.2, onde é possível verificar que a grande mudança de comportamento se dá entre o percentil $95 \%$ e o $98 \%$, mas como o VR atual encontra-se muito distante da distribuição dos veículos bem mantidos, cujo limite é caracterizado pelos percentis p90, p95 e p98, mesmo a faixa entre o p90 e o p95 encontra-se contaminada por veículos com manutenção deficiente, emitindo acima do que seria normal para o modelo e ano de fabricação. Com o VR de 40, muito abaixo do antigo valor de 100, obteve-se apenas $7 \%$ de reprovação adicional com a segurança de eliminação dos falsos positivos. 


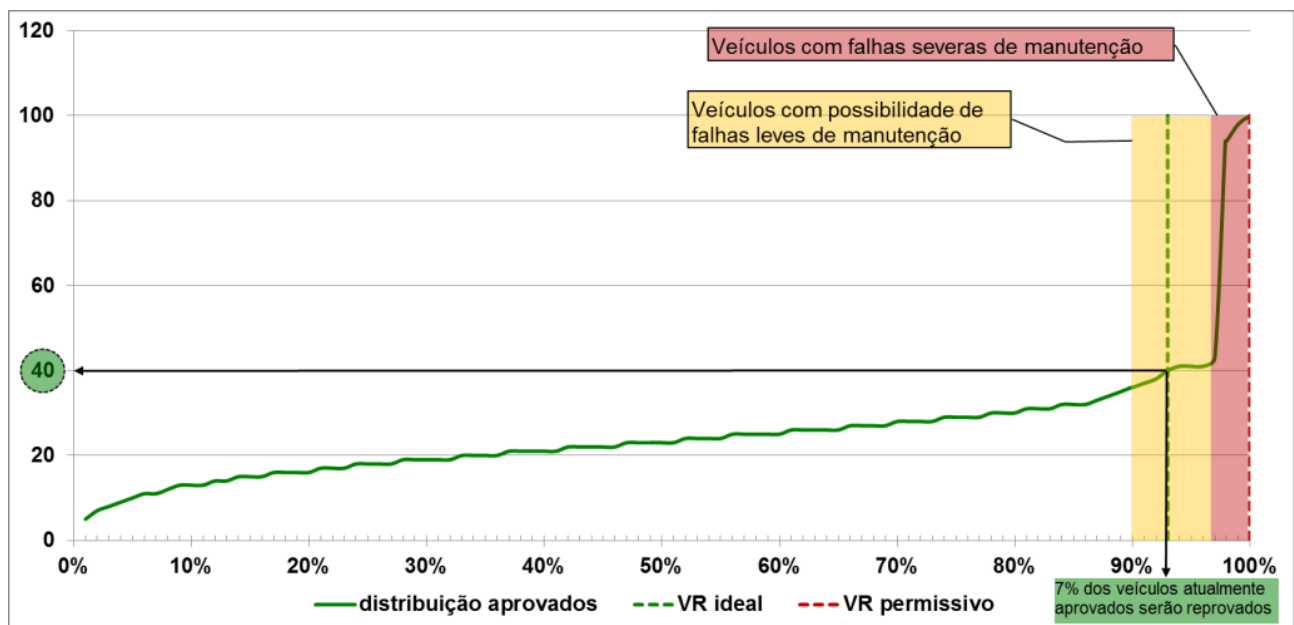

Figura 1.2 - Distribuição percentílica dos veículos aprovados da figura 1.1

Assim, fica claro que neste caso é necessário buscar um VR situado entre o p90 e p95, o que limita o acréscimo de reprovações a $10 \%$ ou $5 \%$, respectivamente, dos veículos aprovados com o limite anterior ao mesmo tempo em que exclui da faixa de aprovação parte dos veículos com manutenção deficiente e aumenta a eficiência do Programa na redução das emissões de poluentes.

$\mathrm{Na}$ prática, a busca por um VR ideal para cada tecnologia deve ser necessariamente um processo de aproximação sucessiva, com a aplicação de valores cada vez mais restritivos até que se obtenha coerência entre os valores de p90, p95, p98 e VR, sendo que a cada novo VR estabelecido é necessário aguardar ao menos dois anos para que a população e a rede de reparação se adaptem à nova regra e os defeitos existentes sejam identificados corrigidos paulatinamente.

Em diversos casos, observa-se que o VR atual encontra-se muito próximo ao valor do p98, o que poderia indicar que o VR estaria condizente com os padrões de emissão. Entretanto, esse fato também pode decorrer da manutenção do veículo ser feita, em muitos casos, apenas quando ocorre uma reprovação, de forma que, se o VR estiver muito folgado em relação ao que o veículo pode atingir (VC), a manutenção preventiva pode não ter sido realizada e as emissões do veículo estejam elevadas em relação ao padrão tecnológico para o seu modelo.

Nestes casos é necessário avaliar a forma do histograma de frequências dos valores de emissão para verificar se existe mais de um conjunto de dados entre os veículos que foram inicialmente aprovados. Caso o histograma seja bimodal, a curva correspondente à primeira moda corresponde aos veículos que realmente apresentam bom estado de manutenção, enquanto que a segunda, é composta por veículos com manutenção deficiente, mas que foram aprovados em consequência de um VR mais permissivo. A principal dificuldade em se estabelecer um novo VR para estes casos é que dificilmente as duas curvas estarão nitidamente separadas, de modo que pode não existir um limite claro entre veículos com manutenção deficiente e veículos pertencentes aos percentis mais altos da curva dos que apresentam manutenção correta. Outro fator a se considerar é o acréscimo do número de reprovações, que pode ser considerado excessivo caso seja escolhido um novo VR que reprove todos os veículos da segunda curva. A figura 1.3 mostra como exemplo o histograma real das emissões de monóxido de carbono $(\mathrm{CO})$ dos veículos pertencentes à fase L3 do PROCONVE fabricados entre 1997 e 2002 movidos a gasolina. 


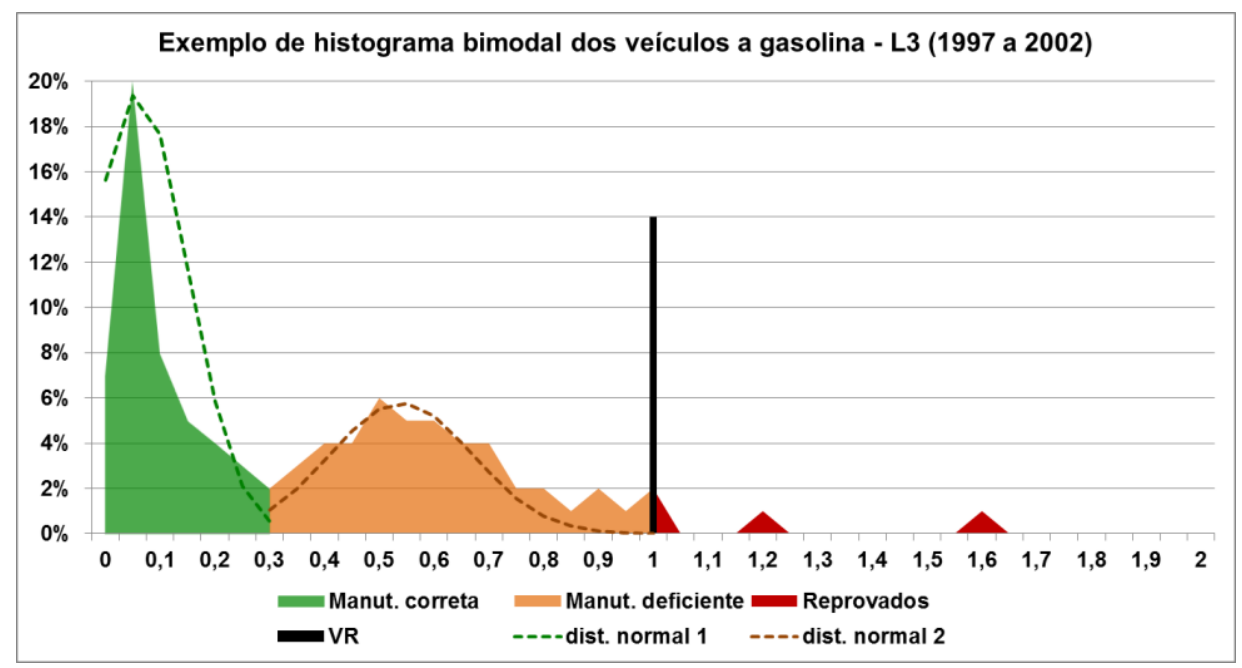

Figura 1.3 - Exemplo de histograma bimodal de CO dos veículos ciclo Otto a gasolina

Observa-se neste caso que existem dois comportamentos essencialmente distintos entre os veículos aprovados, isto é, um com CO menor do que $1 \%$ que é o VR atual e outro com CO abaixo de $0,3 \%$ que corresponde ao valor característico deste padrão tecnológico.

O limite ideal para excluir da faixa dos aprovados os veículos pertencentes à segunda curva, que claramente apresentam manutenção negligente (que leva possivelmente à perda de eficiência do catalisador), seria ao redor de $0,3 \%$ de CO, que é o limite adotado na Europa para este estágio tecnológico. Entretanto, caso se optasse por um VR desta ordem em São Paulo, cerca de 50\% dos veículos desta categoria, que seriam aprovados com o VR atual, teriam de ser reprovados, o que não é estrategicamente recomendável para o Programa. Aqui fica evidente que a ausência do I/M desde 1997, como era previsto, levou a frota a um grau de degradação tão grande, que obriga o Programa a uma recuperação gradual mais lenta do que a desejável, visto a necessidade de se limitar o nível de reprovações. Este fato também explica que a adoção de métodos mais sofisticados seria inútil e desnecessária nesta fase.

Para isso, recomenda-se definir um valor de referência temporário para cada exercício, baseado no p90 dos veículos aprovados do grupo de modelos em questão, levantado no exercício anterior. A título de conscientização pública, deve-se notificar os proprietários, em todos os relatórios de inspeção com resultado superior a $0,3 \%$ de $\mathrm{CO}$, que "este veículo excedeu o valor de referência para a conformidade técnica deste modelo e precisa de manutenção corretiva para ajustá-lo a valores inferiores a 0,3\% de CO, o que poderá ser exigido nos próximos anos". O órgão ambiental local deverá definir novos valores de referência provisórios para cada exercício subsequente, sempre baseado no p90 dos veículos aprovados no último ano, até atingir o valor de referência para efetiva conformidade técnica.

Diante das estatísticas atuais dos veículos da fase L3, a primeira revisão dos seus VR poderia ser proposta em torno de $0,7 \%$ de $\mathrm{CO}$, correspondente ao p90 de todos os aprovados deste grupo a ser reduzido nos anos subsequentes na medida em que os veículos atinjam valores mais condizentes com a tecnologia deste grupo.

Em outros casos, a bimodalidade não é tão evidente, existindo uma faixa significativa na qual não é possível distinguir entre veículos com manutenção adequada e veículos mal mantidos, posto que os dois histogramas encontram-se sobrepostos, como apresentado na figura 1.4.

Diferentemente do exemplo anterior, neste caso o segundo histograma dos veículos aprovados corresponde, provavelmente, a veículos que foram "ajustados para passar na inspeção e reajustados depois", sem que seus defeitos de manutenção tenham sido corrigidos. 
Neste caso, existe uma sobreposição entre os dois comportamentos, sendo que os percentis p90 e p95 encontram-se próximos do VR, de forma que não é possível determinar com exatidão qual o VR ideal para que os veículos com manutenção deficiente sejam reprovados, embora seja possível (e necessário) propor uma pequena redução do VR para valores ao redor de 600 ppm de hidrocarbonetos (HC), faixa em que os dois histogramas se encontram e os percentuais de falsos positivos e de falsos negativos podem ser minimizados.

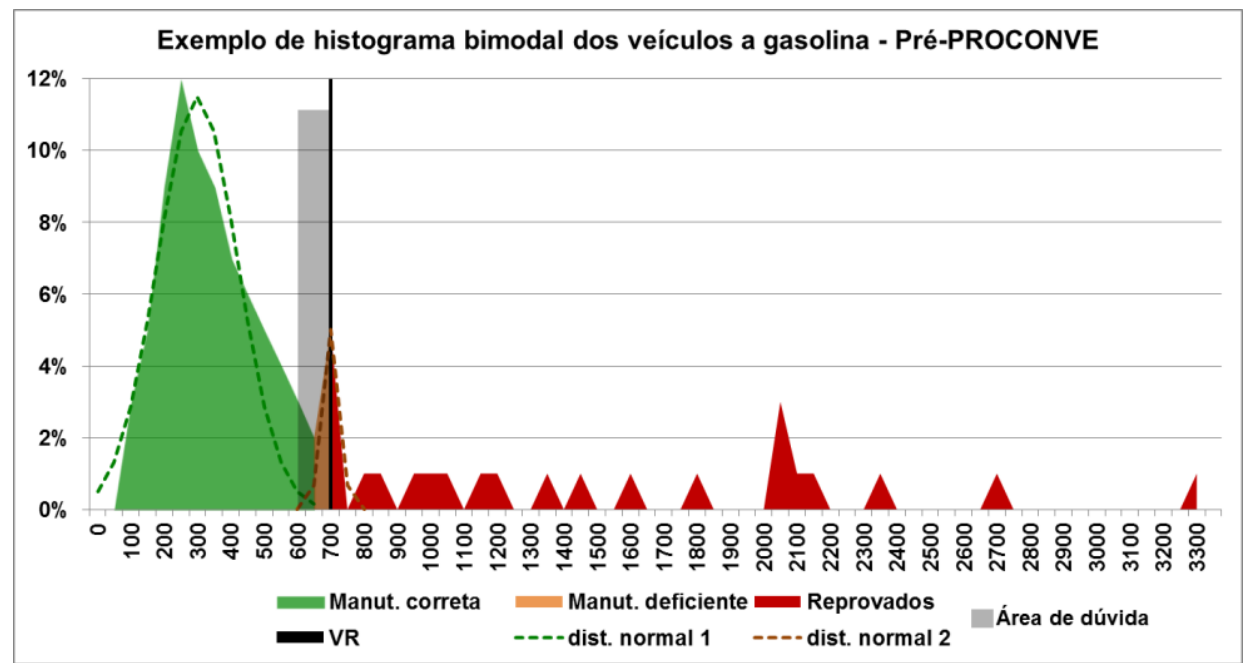

Figura 1.4 - Exemplo de histograma bimodal de HC dos veículos mais antigos, do ciclo Otto a gasolina

\section{Análise estatística dos veículos aprovados em 2012 na cidade de São Paulo e definição das propostas de VR}

Conforme comentado anteriormente, a reavaliação dos VRs com base em valores medidos em Programas I/M deve partir necessariamente da análise estatística das emissões dos veículos aprovados, posto que o que se busca são os padrões apresentados pelos veículos bem mantidos, factíveis no cenário real. Para tanto, é necessário que haja um volume de dados suficiente para conferir consistência às estatísticas de cada fase do PROCONVE, em uma primeira análise, ou de cada ano de fabricação para que possam ser definidos grupos homogêneos em termos dos parâmetros estatísticos considerados. Esta reavaliação deve ser repetida periodicamente após a implantação dos novos VRs, de forma a incorporar o aprendizado da sociedade até que se explore todo o potencial que a manutenção preventiva dos veículos em uso possa oferecer ao controle ambiental sem que isso represente um ônus excessivo para a sociedade.

Entre os veículos aprovados no ano de 2012, conta-se com mais de 2,5 milhões de inspeções aprovadas, seja na inspeção inicial ou após a realização de reparos no veículo e retorno para a reinspeção, as quais se encontram distribuídas segundo a tabela 2.1.

A maioria das curvas percentílicas permitiu avaliar a necessidade de alteração dos VRs, sendo que apenas dois casos (veículos a álcool anteriores a 1979 e veículos a álcool do ano de 1997) apresentaram baixa consistência, por terem menos de duzentas inspeções, e outros cinco, todos de veículos a álcool (sombreados) que não foram incluídos nesta análise por não atingirem o número mínimo de 100 inspeções. 
Tabela 2.1: número de veículos com inspeções aprovadas por combustível em 2012

\begin{tabular}{|c|c|c|c|c|c|}
\hline ano de fabricação & PROCONVE & GASOLINA & FLEX & ÁLCOOL & GNV \\
\hline até 1979 & \multirow{2}{*}{ Pré } & 20949 & & 155 & 221 \\
\hline 1980 a 1988 & & 14120 & & 31932 & 975 \\
\hline 1989 & \multirow{3}{*}{$\mathbf{L 1}$} & 6147 & & 6766 & 502 \\
\hline 1990 & & 11784 & & \begin{tabular}{|l|}
1719 \\
\end{tabular} & 705 \\
\hline 1991 & & 12619 & & 3537 & 717 \\
\hline 1992 & \multirow{5}{*}{$\mathbf{L 2}$} & 11557 & & 5231 & 727 \\
\hline 1993 & & 18998 & & 8647 & 1155 \\
\hline 1994 & & 30702 & & 5758 & 1621 \\
\hline 1995 & & 52946 & & 2222 & 2508 \\
\hline 1996 & & 62350 & & 600 & 3150 \\
\hline 1997 & \multirow{9}{*}{ L3 } & 83262 & & 107 & 3744 \\
\hline 1998 & & 70205 & & 69 & 3372 \\
\hline 1999 & & 59605 & & 293 & 2365 \\
\hline 2000 & & 79128 & & 388 & 2674 \\
\hline 2001 & & 86531 & & \begin{tabular}{|l|}
373 \\
\end{tabular} & 2278 \\
\hline 2002 & & 84207 & & 1213 & 2127 \\
\hline 2003 & & 78029 & 2833 & 798 & 1509 \\
\hline 2004 & & 84200 & 26644 & 1142 & 1479 \\
\hline 2005 & & 61894 & 66726 & 1182 & 1682 \\
\hline 2006 & \multirow{3}{*}{ L4 } & 41782 & 113734 & 10 & 2107 \\
\hline 2007 & & 41232 & 171591 & 1 & 2900 \\
\hline 2008 & & 45626 & 212194 & 2 & 2357 \\
\hline 2009 & \multirow{3}{*}{ L5 } & 33528 & 243293 & & 825 \\
\hline 2010 & & 48731 & 248515 & & 1483 \\
\hline 2011 & & 38507 & 194702 & 1 & 1654 \\
\hline
\end{tabular}

\subsection{Avaliação dos parâmetros estatísticos das emissões de CO e dos VRs atuais}

A seguir, serão apresentados os casos mais significativos para exemplificar a metodologia de análise utilizada para avaliar os VRs.

A figura 2.1 mostra a comparação entre os VRs atuais e os parâmetros estatísticos dos veículos a gasolina, definidos como mais significativos para caracterizar os níveis de emissão que os veículos podem efetivamente atingir com a manutenção normalmente feita pela população (média, p90, p95 e p98), por ano de fabricação.

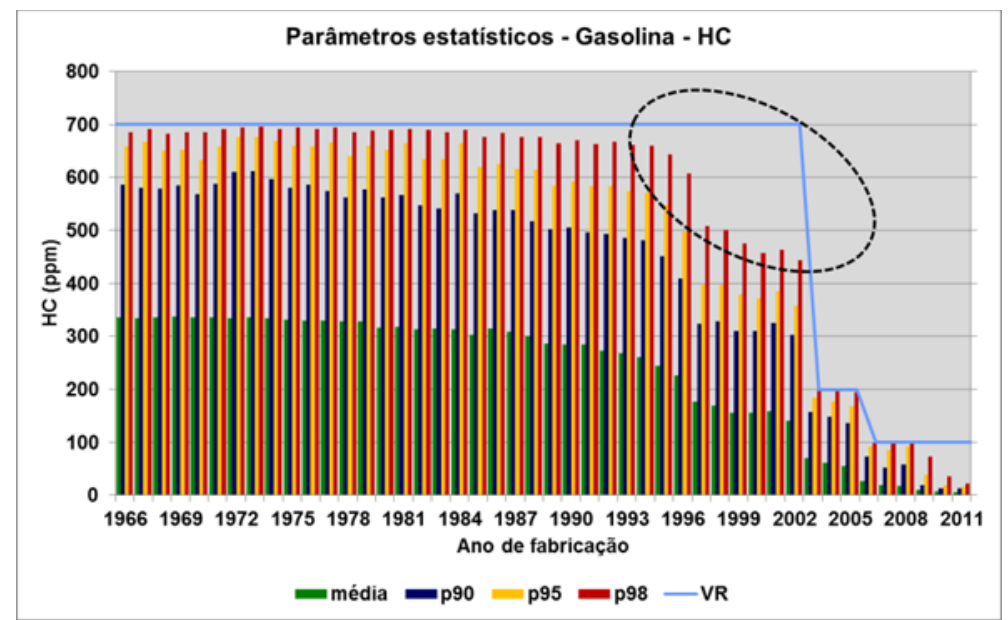

Figura 2.1 - Parâmetros estatísticos de HC e os respectivos VRs para cada ano de fabricação 
No caso dos veículos L3 fabricados entre 1997 e 2002, os percentis de $98 \%$ das medições de HC encontram-se muito distantes do VR atual de 700 ppm, e a distância entre os percentis de 90\% a 98\% também aumenta, indicando que este VR se encontra muito leniente, de modo que a inspeção baseada no VR atual exerce pouco controle sobre o nível de manutenção.

Outra abordagem que leva à interpretação da necessidade de ajuste no VR desse grupo de veículos é a análise do histograma de frequências dos valores de $\mathrm{HC}$ medidos. Este histograma mostra um comportamento bimodal, com grande parte dos veículos aprovados na segunda moda, indicando que o ajuste do VR destes veículos deve ser feito de forma gradual, de modo a diluir o impacto das reprovações, conforme comentado anteriormente (figura 2.2).

Assim, em uma primeira etapa poderia ser adotado o valor de 300 ppm como VR, eliminando os veículos situados no topo da segunda moda ou acima dela para, em seguida, reduzir novamente o VR, agora para 200 ppm que aparentemente corresponde ao final da distribuição dos veículos com a manutenção correta. Após este processo, o estudo deve ser repetido necessariamente, à medida que a maioria dos defeitos seja corrigida, para determinar qual o valor que efetivamente pode ser atendido com a manutenção correta.

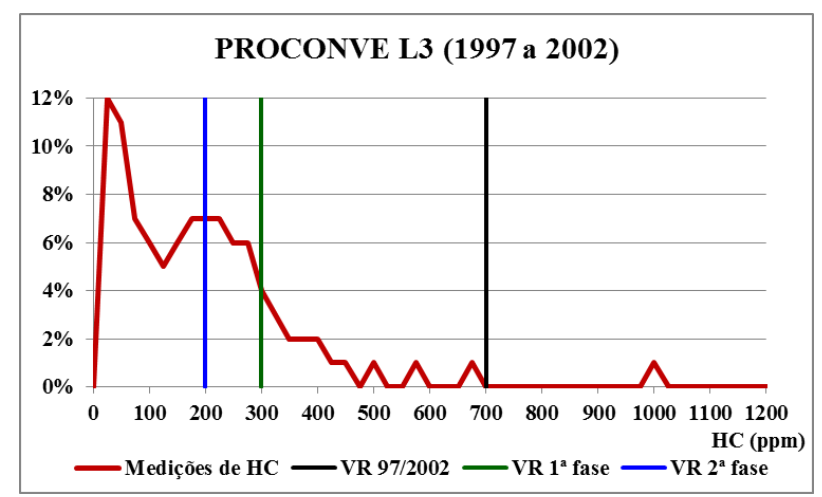

Figura 2.2 - Histogramas dos valores de emissão de HC dos veículos a gasolina fabricados entre 1997 e 2002

No caso do CO, o mesmo grupo não apresenta o VR distante do P98, mas o histograma bimodal mostra também a necessidade de ajustes, a serem feitos de forma gradual, nos valores de $0,7 \%$ e $0,3 \%$ (figura 2.3 ). Note-se que, no histograma do $\mathrm{CO}$, a segunda moda termina muito próximo do VR, o que resulta na proximidade observada entre o VR e o P98, indicando a necessidade de efetuar a análise completa, baseada nos dois tipos de informações. Provavelmente isto se deve ao fato de que aumentos exagerados de $\mathrm{CO}$ decorrem da desregulagem do motor, enquanto que os de $\mathrm{HC}$ também estão associados à queima de óleo devida ao desgaste do motor e, por isso são menos frequentes.

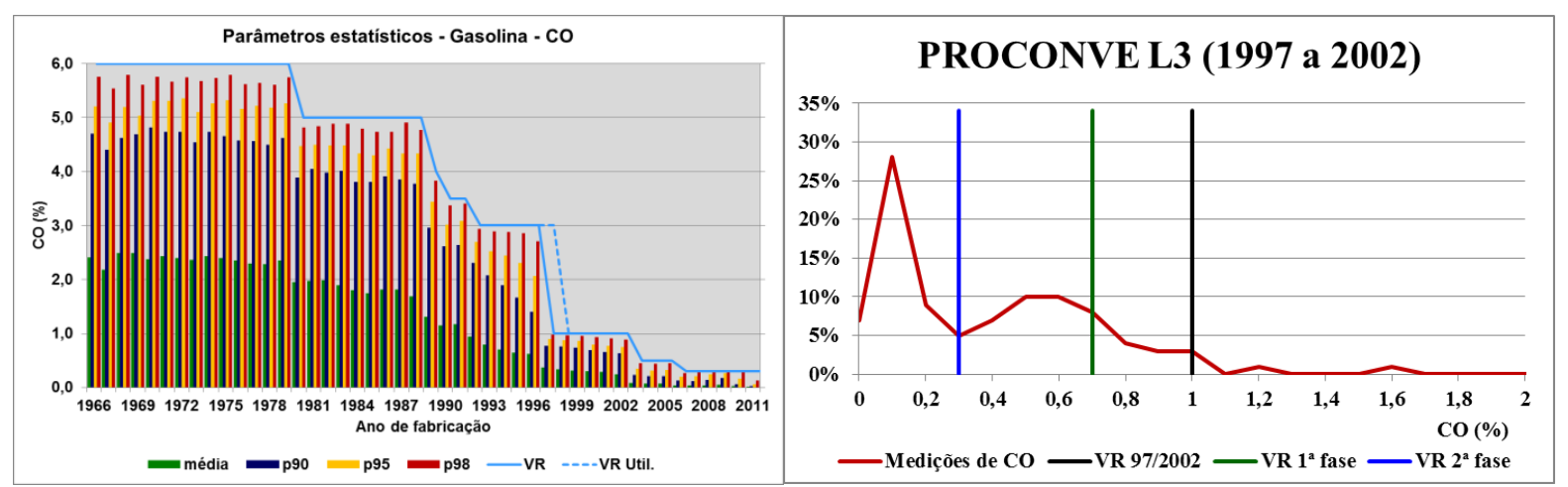

Figura 2.3 - Parâmetros estatísticos e histogramas dos valores de emissão de CO dos veículos a gasolina fabricados entre 1997 e 2002 
Adicionalmente, uma análise feita comparando o percentual de rejeições com o de reprovações nas medições de $\mathrm{CO}$ e $\mathrm{HC}$ mostra uma grande coerência em todos os anos de fabricação, exceto para os veículos fabricados entre 1995 e 2002, onde se verifica que o nível de reprovações cai significativamente em relação às rejeições, o que indica menor severidade dos VRs deste grupo em relação aos demais (figura 2.4).

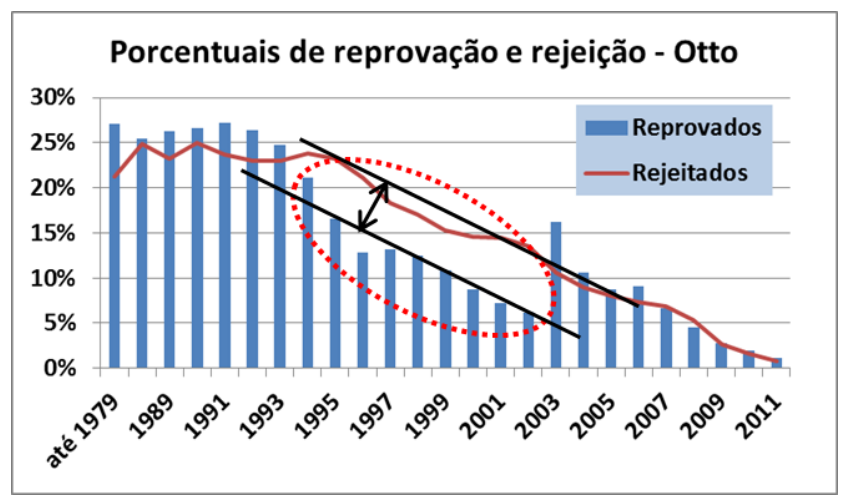

Figura 2.4 - Coerência da inspeção visual e de gases por ano de fabricação

Análises semelhantes foram feitas para todos os tipos de combustíveis e idades dos veículos, resultando em um conjunto de valores propostos para aplicação em uma ou duas etapas, conforme o caso, os quais deverão ser reavaliados no mínimo um ano após a sua implantação.

\subsection{Considerações adicionais sobre os veículos convertidos para GNV}

O problema das conversões de motores para outros combustíveis não se limita à análise das emissões em marcha lenta, pois a calibração do motor é necessariamente alterada nos demais regimes de funcionamento e geralmente altera a calibração original do motor em toda a sua extensão. A figura 2.5 apresenta o comportamento médio das conversões e no extremo da sua variação estatística, entre os veículos considerados em boas condições de manutenção (aprovados na inspeção atual) e mostra estes aspectos com mais clareza: enquanto a média indica que a aplicação de GNV em veículos fabricados até 2002 pode trazer reduções de emissão com os dois combustíveis, os percentis mais elevados demonstram que os veículos convertidos ficam ainda piores do que os piores veículos não convertidos, especialmente nos modelos posteriores a 2003 funcionando com GNV, para os quais a Resolução 418/2009 fez uma atualização dos VRs. Tais fatos devem-se à precariedade da certificação das conversões.

As reduções de emissão observadas nos veículos convertidos e funcionando com o combustível original são particularmente preocupantes porque indicam que o projeto original foi alterado a ponto de perder a estequiometria da combustão, descaracterizando a conformidade do motor com as fases L3 e seguintes. Este fato contraria os objetivos do Programa I/M de assegurar a conformidade dos veículos em uso com as suas características certificadas pelo IBAMA. Desta forma, estes veículos deveriam ter sido conceitualmente reprovados na certificação da conversão, por terem perdido o controle da estequiometria indispensável ao correto funcionamento do catalisador, apesar de mostrarem menores valores nas emissões de $\mathrm{CO}$ e $\mathrm{HC}$ em marcha lenta que, provavelmente, correspondem a elevações da emissão de NOx, como já foi constatado em amostragens por sensoriamento remoto.

Nos modelos 2003 em diante, é flagrante que a conversão sempre piora a emissão, dado o melhor nível tecnológico introduzido nos veículos a partir dos lançamentos para a fase L4 do PROCONVE: os VRs mais baixos dos veículos a gasolina destes anos de fabricação refletem esta melhoria tecnológica e o seu posterior desperdício com as conversões para GNV. Além 
disso, não há certificações do IBAMA para kits de conversão para aplicações em veículos fabricados a partir de $2007^{[5]}$, tornando-as irregulares perante a legislação ambiental.
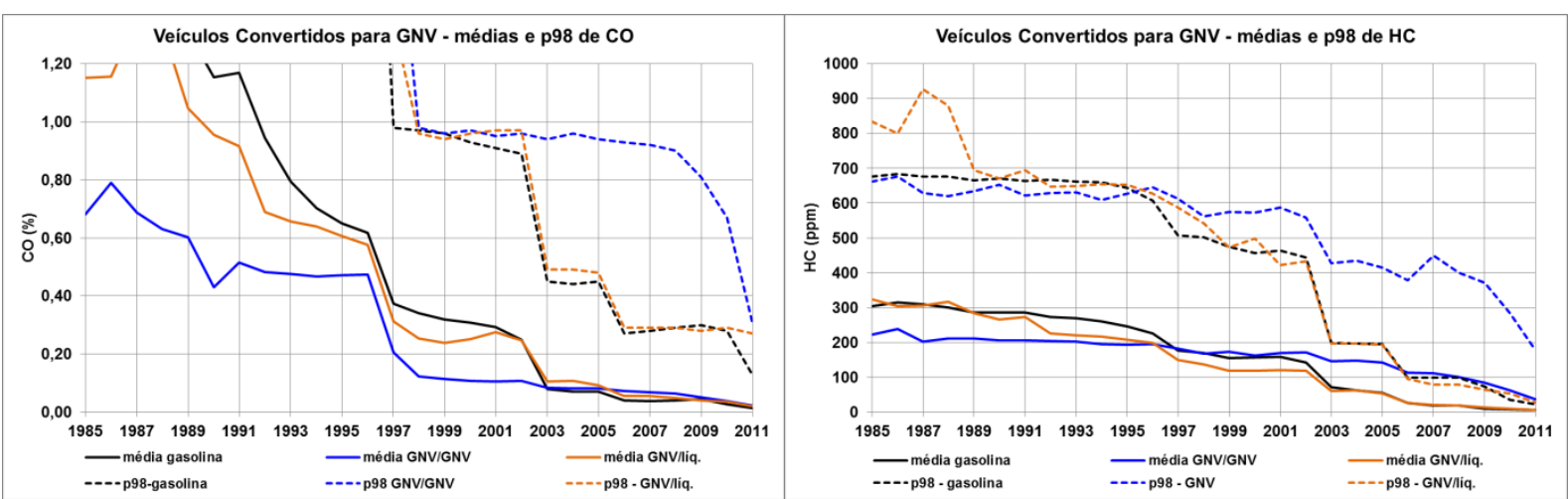

Figura 2.5 - Efeitos da conversão para GNV sobre as emissões de CO e HC em marcha lenta

\section{Valores de Referências propostos}

Com base nas análises estatísticas descritas são propostos novos VRs cuja aplicação deve ser feita após o segundo ano de funcionamento de qualquer Programa de I/M no país, sendo necessário o contínuo acompanhamento estatístico das medições, de forma a buscar os melhores valores possíveis, minimizando o impacto sobre os índices de reprovação.

Nas tabelas a seguir, os VRs futuros são geralmente apresentados para as duas fases de revisão propostas, sendo que os valores da segunda fase deverão ser ratificados com base em novas estatísticas obtidas após a implantação da primeira.

Cabe ressaltar que, para os veículos convertidos para GNV, os VR propostos para quando o veículo utiliza o combustível original - gasolina, etanol ou suas misturas - é o mesmo do veículo original, posto que a conversão para GNV é um procedimento que dispensa nova homologação e, portanto, não deveria aumentar as emissões do veículo quando funcionando com o combustível original.

Tabela 3.1: Valores de referência de $\mathrm{CO}$ propostos para veículos a gasolina

\begin{tabular}{|l|l|l|l|}
\hline Ano de fabricação & VR atual & VR $\mathbf{1}^{\text {a }}$ fase (\%) & VR $\mathbf{2}^{\mathbf{a}}$ fase (\%) \\
\hline Até 1979 & 6,0 & 5,20 & 4,50 \\
\hline $\mathbf{1 9 8 0}$ a 1988 & 5,0 & 4,40 & 4,00 \\
\hline $\mathbf{1 9 8 9}$ & 4,0 & 3,40 & 3,00 \\
\hline $\mathbf{1 9 9 0}$ e $\mathbf{1 9 9 1}$ & 3,5 & 3,10 & 2,50 \\
\hline $\mathbf{1 9 9 2}$ a 1996 & 3,0 & 2,50 & 1,70 \\
\hline $\mathbf{1 9 9 7}$ a 2002 & 1,0 & 0,70 & 0,30 \\
\hline $\mathbf{2 0 0 3}$ a 2005 & 0,5 & 0,30 & 0,20 \\
\hline $\mathbf{2 0 0 6}$ em diante & 0,3 & 0,30 & 0,15 \\
\hline
\end{tabular}

Tabela 3.2: Valores de referência de HC propostos para veículos a gasolina

\begin{tabular}{|l|l|l|l|}
\hline Ano de fabricação & VR atual (ppm) & ${\text { VR } \mathbf{1}^{\mathbf{a}} \text { fase (ppm) }}$ & VR 2 $^{\mathbf{a}}$ fase (ppm) \\
\hline Até 1984 & 700 & 650 & 600 \\
\hline $\mathbf{1 9 8 5}$ a 1988 & 700 & 620 & 550 \\
\hline $\mathbf{1 9 8 9}$ a 1996 & 700 & 570 & 500 \\
\hline $\mathbf{1 9 9 7}$ a 2002 & 700 & 300 & 200 \\
\hline $\mathbf{2 0 0 3}$ a 2005 & 200 & 180 & 120 \\
\hline $\mathbf{2 0 0 6}$ a 2008 & 100 & 90 & 50 \\
\hline $\mathbf{2 0 0 9}$ em diante & 100 & 40 & 20 \\
\hline
\end{tabular}


Tabela 3.3: Valores de referência para CO propostos para veículos a etanol

\begin{tabular}{|c|c|c|c|}
\hline Ano de fabricação & VR atual (\%) & VR $1^{\text {a }}$ fase $(\%)$ & VR $2^{a}$ fase $(\%)$ \\
\hline Até 1988 & 5,0 & 4,3 & 3,5 \\
\hline 1989 & 4,0 & 3,4 & 3,0 \\
\hline 1990 e 1991 & 3,5 & 3,0 & 2,5 \\
\hline 1992 a 1996 & 3,0 & 2,7 & 2,2 \\
\hline 1997 a 2002 & 1,0 & 0,8 & 0,5 \\
\hline 2003 em diante & 0,5 & 0,3 & 0,2 \\
\hline
\end{tabular}

Tabela 3.4: Valores de referência de HC propostos para veículos a etanol

\begin{tabular}{|l|l|l|l|}
\hline Ano de fabricação & VR Atual (ppm) & VR 1 $^{\mathbf{a}}$ fase (ppm) & VR 2 $^{\mathbf{a}}$ fase (ppm) \\
\hline Até 1991 & 1.100 & 950 & 800 \\
\hline $\mathbf{1 9 9 2}$ a 1996 & 700 & 630 & 550 \\
\hline $\mathbf{1 9 9 7}$ e 1998 & 700 & 450 & 350 \\
\hline $\mathbf{1 9 9 9}$ a 2002 & 700 & 380 & 300 \\
\hline $\mathbf{2 0 0 3}$ em diante & 250 & 190 & 120 \\
\hline
\end{tabular}

Tabela 3.5: Valores de referência de CO propostos para veículos flex

\begin{tabular}{|l|l|l|l|}
\hline Ano de fabricação & VR Atual (\%) & VR $\mathbf{1}^{\mathbf{a}}$ fase (\%) & VR 2a fase (\%) \\
\hline $\mathbf{2 0 0 3}$ a 2005 & 0,50 & 0,20 & 0,10 \\
\hline $\mathbf{2 0 0 6}$ a 2008 & 0,3 & 0,15 & 0,10 \\
\hline 2009 em diante & 0,3 & 0,10 & 0,05 \\
\hline
\end{tabular}

Tabela 3.6: Valores de referência de HC propostos para veículos flex

\begin{tabular}{|l|l|l|l|}
\hline Ano de fabricação & VR Atual (ppm) & VR 1 $\mathbf{1}^{\mathbf{a}}$ fase (ppm) & VR 2 $^{\mathbf{a}}$ fase (ppm) \\
\hline $\mathbf{2 0 0 3}$ a 2005 & 200 & 120 & 80 \\
\hline 2006 a 2008 & 100 & 60 & 40 \\
\hline 2009 em diante & 100 & 25 & 25 \\
\hline
\end{tabular}

Tabela 3.7: Valores de referência de CO propostos para veículos funcionando com GNV

\begin{tabular}{|c|c|c|c|}
\hline Ano de fabricação & VR atual (\%) & VR $1^{a}$ fase $(\%)$ & VR $2^{a}$ fase $(\%)$ \\
\hline Até 1988 & 5,0 & 2,50 & 1,50 \\
\hline 1989 & 4,0 & 2,40 & 1,50 \\
\hline 1990 e 1991 & 3,5 & 2,30 & 1,50 \\
\hline 1992 a 1996 & 3,0 & 2,30 & 1,50 \\
\hline 1997 a 2005 & 1,0 & 0,70 & 0,40 \\
\hline 2006 & 1,0 & 0,60 & 0,20 \\
\hline 2007 e $2008^{(*)}$ & 1,0 & 0,30 & 0,15 \\
\hline 2009 em diante ${ }^{(*)}$ & 1,0 & 0,30 & 0,10 \\
\hline
\end{tabular}

(*) para estes períodos não há kits de conversão homologados pelo IBAMA. O único modelo fabricado originalmente para uso de GNV pode atender aos VRs dos veículos flex.

Tabela 3.8: Valores de referência de $\mathrm{HC}$ propostos para veículos funcionando com GNV

\begin{tabular}{|l|l|l|l|}
\hline Ano de fabricação & VR Atual (ppm) & VR $\mathbf{1}^{\mathbf{a}}$ fase (ppm) & VR $\mathbf{2}^{\mathbf{a}}$ fase (ppm) \\
\hline Até 1988 & 700 & 530 & 400 \\
\hline $\mathbf{1 9 8 9}$ a 1996 & 700 & 500 & 400 \\
\hline $\mathbf{1 9 9 7}$ a 2002 & 700 & 450 & 350 \\
\hline $\mathbf{2 0 0 3}$ a 2005 & 500 & 340 & 270 \\
\hline $\mathbf{2 0 0 6}$ a 2008 & $(*)$ & 250 & 220 \\
\hline 2009 em diante ${ }^{(*)}$ & 500 & 40 & 30 \\
\hline
\end{tabular}

(*) para estes períodos não há kits de conversão homologados pelo IBAMA. O único modelo fabricado originalmente para uso de GNV pode atender aos VRs dos veículos flex. 


\section{Avaliação das propostas de VRs frente aos valores característicos dos modelos de veículos}

As uniformizações entre os VRs dos diversos tipos de combustível mencionados acima são desejáveis para simplificar a regulamentação e evitar enganos quanto à sua aplicação a cada veículo. Para melhor benefício sobre a qualidade do ar, é recomendável que este nivelamento contemple os menores valores atribuídos a cada categoria, desde que não sejam exceções tecnologicamente privilegiadas para se evitar o risco de dificultar excessivamente o atendimento de alguns modelos de veículos. Para evitar estas incompatibilidades, os VR devem ser escolhidos de forma que as exceções sejam mínimas, se existentes, e tais modelos deverão ser identificados numa tabela com VRs específicos, como discutido a seguir.

Uma vez definidos os VRs para cada tecnologia e ano de fabricação, é possível compará-los com os VCs de todos os modelos inspecionados, para verificar quais são as marcas ou modelos em particular que apresentam eventuais dificuldades em atender aos valores propostos a partir das estatísticas da frota em geral. Os valores característicos dos veículos são níveis de emissão correspondentes aos percentis de 50\%, 75\% e 90\% da frota aprovada de cada modelo em separado.

A confrontação desses valores, modelo a modelo, com os VRs aqui determinados permite verificar o grau de dificuldade que cada modelo terá para atender ao VR proposto em função das suas características de projeto, identificando inclusive a eventual necessidade de estabelecimento de um VR especial para determinados modelos, caso seus VCs demonstrem haver dificuldade em atende-los. A seguir, são apresentados dois exemplos para os quais estão destacados modelos e marcas cujo percentil p90 dos veículos aprovados encontram-se acima dos VRs propostos, ou seja, que teriam mais de $10 \%$ de reprovação dos veículos atualmente aprovados.

Estes exemplos foram avaliados como exercício para a definição do procedimento analítico e cabe ressaltar que, para o desenvolvimento completo desta análise, ainda será necessário determinar os valores característicos dos diferentes modelos segregando-os por combustível. Para os veículos mais novos (fase L5), é aconselhável segregá-los por ano de fabricação caso haja volume suficiente de dados que permita a elaboração de curvas percentílicas consistentes para cada modelo e ano de fabricação. Como o detalhamento desta análise estatística envolve um grande trabalho de processamento de dados, o cruzamento completo dos VRs propostos com os valores característicos de cada modelo, esta etapa deve ser realizada em uma segunda rodada, quando a ideia da revisão for aceita, os VRs propostos forem considerados plausíveis e estas propostas forem discutidas.

Para mostrar como esta discussão poderá ser conduzida, a figura 4.1 (gráfico superior) apresenta os limites propostos para os veículos a gasolina e flex propostos para os períodos 2003-2005 e 2006-2011 comparados aos valores p50, p75 e p90 característicos de cada modelo, cujo p90 exceda tais limites. Nesta abordagem preliminar, foram detectados 56 modelos das fase L3/L4 que teriam maior dificuldade em atender o VR de 0,25\% de CO, os quais correspondem a $27 \%$ da frota atualmente aprovada. Se o VR for elevado a $0,30 \%$, esta reprovação adicional cairá para $8 \%$ (35 modelos) o que é uma melhor recomendação para que a lista de exceções seja reduzida sem grandes prejuízos ambientais. Inversamente, se o VR fosse elevado a $0,35 \%$ de $\mathrm{CO}$, a reprovação adicional cairia para $6 \%$ (28 modelos), o que não se justifica pela comparação dos p90. Entretanto, o VR de $0,35 \%$ de CO praticamente elimina a ocorrência de reprovações aos níveis dos valores característicos dos p75 de alguns modelos, o que poderia ser justificável para reduzir o número de reclamações. 
Após uma análise mais detalhada seguindo estes critérios, os VRs resultantes deverão compor uma simulação para a previsão final do aumento das reprovações da frota em geral.

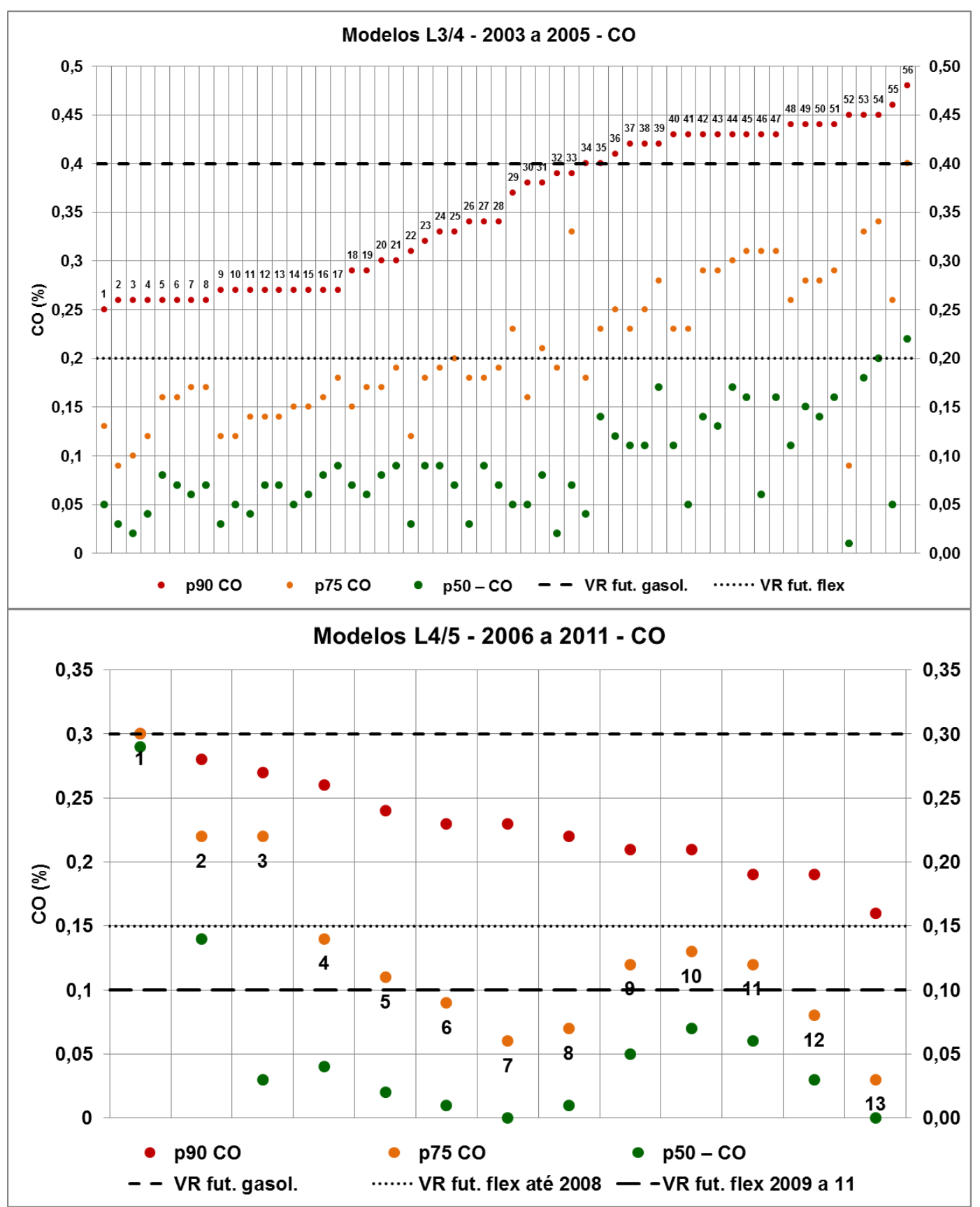

Figura 4.1 - Exemplos de avaliação das propostas iniciais de ajuste dos VRs com base no p90 dos modelos de automóveis inspecionados

\section{Considerações acerca dos desvios de medição}

Todos os VRs propostos neste trabalho são baseados nas análises estatísticas das medições efetuadas. Como o universo estatístico dos resultados destas medições é muito grande, os parâmetros determinados para o cálculo dos VRs (p90, p95, p98 etc.) são virtualmente isentos de erro, levando a valores sem margens de tolerância para os desvios de origem das medições, e representam os valores que os veículos são efetivamente capazes de atender. 
Por isso, a sua utilização requer a identificação dos erros máximos inerentes ao processo de medição (erros do equipamento e de contaminação da sonda de amostragem) para serem descontados do valor medido e o posterior confronto com os VRs propostos neste trabalho, como estabelece o INMETRO, para qualquer tipo de medição.

Operacionalmente, pode ser adotada uma tolerância fixa e característica do processo de medição, determinada previamente a partir dos equipamentos e procedimentos utilizados, limitada a um valor máximo a ser fixado pelo CONAMA. No passado, esta tolerância estava incluída nos "limites de emissão para inspeção e manutenção", o que levou a Resolução CONAMA 418/2009 a estabelecer "limites" (valores de referência atuais) suficientemente lenientes para contemplar os erros de medição e outras interferências que pudessem desencadear falsas reprovações, assim admitido por falta de dados mais precisos da própria frota circulante. Entretanto, esta incorporação dos erros aos VRs causa críticas de pessoas que, por desconhecerem o fato, sugerem que os erros de medição sejam novamente descontados. O desenvolvimento do Programa de I/M-SP evidenciou a oportunidade de serem separados os VRs e as tolerâncias, de forma a permitir a otimização destas últimas para evitar folgas desnecessárias, levando à elaboração deste estudo para a substituição dos limites atuais por Valores de Referência dos veículos e a definição das tolerâncias admissíveis diretamente associadas ao sistema de medições.

\subsection{Desvios inerentes ao processo de medição}

Conforme Portaria Inmetro n. ${ }^{\circ} 155$, de 12 de agosto de 2005 os desvios inerentes aos equipamentos são basicamente de duas naturezas, além dos que se propagam através dos cálculos, como ocorre na correção dos resultados pelo fator de diluição.

Esta Portaria aponta quatro níveis de erros característicos dos equipamentos das classes 0 e I:

- erros intrínsecos: erros medidos pelos fabricantes, sob as condições de referência;

- erros na verificação inicial: erros medidos pelos fabricantes em equipamentos novos, $\underline{\text { sob }}$ as condições de operação;

- erros nas verificações periódica e eventual: erros medidos pelos fabricantes em revisões periódicas dos equipamentos (tipicamente, anuais), ou quando da sua manutenção eventual, sob as condições de operação; e

- erros na medição em serviço: erros medidos pelo usuário ou órgão fiscalizador durante o período de operação normal, entre as revisões, sob as condições de operação.

A Portaria é baseada no Documento Internacional n. ${ }^{\circ} 11$, ed. 1994, da OIML e na Recomendação Internacional n. ${ }^{\circ}$ 99/Norma ISO 3930, ed. 2000. Em 2008, a OIML publicou uma atualização da Recomendação R99 (International Recommendation R99-1 \& 2, edition 2008), correspondente à Norma ISO PAS 3930, edição 2009, que adiciona novas recomendações para equipamentos ainda mais precisos, criando a classe 00 , e já descarta o emprego de equipamentos analógicos para este fim.

\section{a) erros característicos do equipamento}

Os erros intrínsecos dos equipamentos são estabelecidos em condições de referência e são os mesmos prescritos pela OIML e pelo INMETRO para certificação de modelo dos analisadores, sendo considerados adequados para esta finalidade. 
Os desvios existentes nas medições referem-se à imprecisão do equipamento nas condições de operação, podendo gerar erros aleatórios de medição, característicos de cada equipamento em particular. Assim, nos parâmetros estatísticos gerados por milhares de medições feitas por dezenas de equipamentos diferentes, os desvios tendem a se anular mutuamente. Desta forma, pode-se afirmar que os VRs aqui definidos são isentos desse tipo de desvio, pois as medidas de variabilidade dos parâmetros assim determinados são inversamente proporcionais à raiz quadrada do número de dados que gerou a estatística.

Para considerar o desvio de cada inspeção, uma alternativa segura para evitar falsas reprovações baseia-se no erro característico de cada equipamento em particular, determinado na sua verificação metrológica, cujo valor máximo deve ser descontado em cada medição feita por esse equipamento.

Os erros máximos aceitáveis para equipamentos das classes 0 e I segundo a Portaria do INMETRO são iguais aos constantes da recomendação da OIML de 2008, entretanto a OIML não estabelece padrões diferenciados para as verificações periódicas ou eventuais, indicando que os erros máximos admissíveis nas verificações subseqüentes devem ser iguais aos da verificação inicial, enquanto que o INMETRO ainda permite erros maiores para as verificações periódicas e eventuais, e ainda maiores para as medições em serviço.

Como a recomendação da OIML de 2008 é mais atual e abrangente, e os VRs aqui propostos para os veículos flex chegam a valores muito baixos, tornando inadequadas as tolerâncias estabelecidas para as verificações periódicas, eventuais e em serviço, optou-se por tomar como base a International Recommendation R99-1 \& 2 da OIML, edição 2008, em substituição à Portaria do INMETRO, que precisa ser atualizada.

Desta forma, este estudo será baseado nos erros máximos admissíveis nas condições normais de operação dos equipamentos segundo a OIML 99:2008, que estão apresentados na tabela 5.1 e são aplicáveis às certificações e às verificações inicial, periódicas e eventuais da calibração do equipamento.

Tabela 5.1 - Erros máximos admissíveis em condições normais de utilização

\begin{tabular}{|c|c|c|c|c|c|}
\hline Classe & Tipo de erro & CO (\% vol) & $\mathbf{C O}_{\mathbf{2}}$ (\% vol) & $\mathbf{O}_{\mathbf{2}}$ (\% vol) & HC (ppm vol) \\
\hline \multirow{2}{*}{00} & Absoluto (vol) & $\pm 0,02$ & $\pm 0,3$ & $\pm 0,1$ & \pm 4 \\
\cline { 2 - 6 } & Relativo (\%) & $\pm 5 \%$ & $\pm 5 \%$ & $\pm 5 \%$ & $\pm 5 \%$ \\
\hline \multirow{2}{*}{0} & Absoluto (vol) & $\pm 0,03$ & $\pm 0,5$ & $\pm 0,1$ & \pm 10 \\
\cline { 2 - 6 } & Relativo (\%) & $\pm 5 \%$ & $\pm 5 \%$ & $\pm 5 \%$ & $\pm 5 \%$ \\
\hline \multirow{2}{*}{ I } & Absoluto (vol) & $\pm 0,06$ & $\pm 0,5$ & $\pm 0,1$ & \pm 12 \\
\cline { 2 - 6 } & Relativo (\%) & $\pm 5 \%$ & $\pm 5 \%$ & $\pm 5 \%$ & $\pm 5 \%$ \\
\hline
\end{tabular}

\section{b) aderência de HC}

É a presença de resíduos orgânicos aderidos à sonda de amostragem, remanescentes de medições anteriores. Conforme a Resolução CONAMA 418/2009, a Portaria citada e as normas internacionais, a concentração residual de HC na sonda deve ser limitada a 20 ppm, acima da qual a medição não poderá ser efetuada. Este é um erro inerente ao processo de medição, cuja interferência é a soma de valores residuais à medição.

Neste estudo, este erro foi considerado nulo nestas determinações de VR porque as medições realizadas pela Controlar minimizaram esta contaminação por meio da injeção de ar comprimido na sonda antes de cada medição, tornando os valores de HC residuais 
desprezíveis. A prova disto é que, no caso dos veículos flex pertencentes à fase L5, 95\% dos valores medidos nos veículos aprovados estão abaixo de $20 \mathrm{ppm}$, o que implica que a contaminação da sonda e a emissão do veículo somadas são inferiores a este limite, em mais de $95 \%$ das vezes, sendo $16 \%$ dos valores abaixo de $1 \mathrm{ppm}$.

Como os valores propostos para os veículos mais modernos se aproximam da concentração residual permitida, a concentração de $\mathrm{HC}$ efetivamente medida antes do início da amostragem deverá ser descontada da emissão medida no veículo, pois sua interferência poderá ser significativa nos novos VRs.

\section{c) erro do fator de diluiçãa}

O fator de diluição é utilizado para identificar a presença de ar falso nos gases de escapamento e corrigir os valores medidos para descontar eventuais diluições.

$$
\begin{aligned}
& F_{\text {diluição }}=\frac{15}{\left(\mathrm{CO}+\mathrm{CO}_{2}\right)_{\text {medidos }}} \text {, para motores a etanol ou gasolina; } \\
& F_{\text {diluição }}=\frac{12}{\left(\mathrm{CO}+\mathrm{CO}_{2}\right)_{\text {medidos }}} \text {, para motores funcionando com GNV. }
\end{aligned}
$$

As emissões de $\mathrm{CO}_{\mathrm{c}}$ e de $\mathrm{HC}_{\mathrm{c}}$ (corrigidas quanto à diluição) são obtidas a partir da multiplicação dos respectivos valores medidos pelo fator de diluição e, portanto, os erros de cada medição se combinam e conduzem o processo a um erro total maior do que os erros considerados individualmente. A figura 5.1 apresenta a dependência entre o valor de $\mathrm{CO}_{\mathrm{c}} \mathrm{e} \mathrm{o}$ valor real de $\mathrm{CO}$, até $0,5 \%$ onde as diferenças entre as classes são mais expressivas, em função dos valores medidos de $\mathrm{CO}$ e $\mathrm{CO}_{2}$, consideradas as tolerâncias estabelecidas para os equipamentos Classe 0 e I, nas quatro combinações dos erros máximos positivos e negativos estabelecidos pela OIML 99:2008.
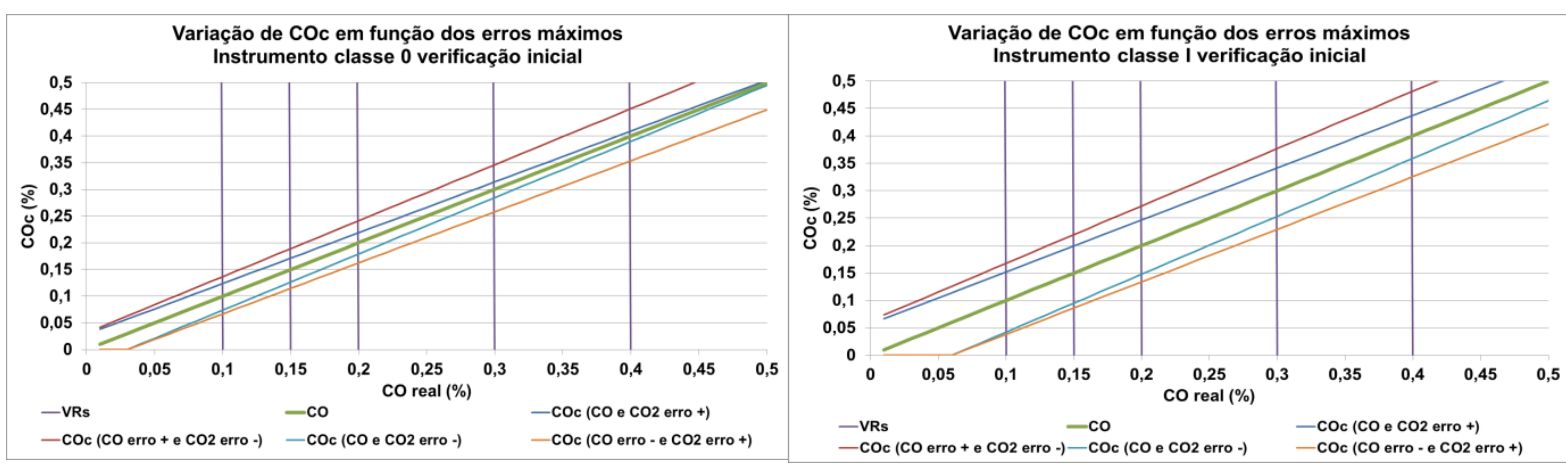

Figura 5.1 - Influência das tolerâncias sobre os resultados absolutos de COc para equipamentos das classes 0 e I

Com base nos valores calculados acima, o erro relativo de $\mathrm{COc}$ foi calculado em função do valor real de $\mathrm{CO}$, conforme apresentado na figura 5.2 para equipamentos Classes 0 e I. Esta análise mostra que para valores de $\mathrm{CO}$ abaixo de $0,2 \%$, o erro total dos equipamentos torna-se bastante significativo para a avaliação dos resultados, sendo necessária aplicação de equipamentos classe 0. A partir destas curvas, será possível avaliar os erros máximos admissíveis para cada VR, conforme a classe de equipamento escolhida, que deverão ser considerados nas medições futuras. 
No caso das medições de HC, estas curvas tornam-se mais complexas porque dependem dos erros do fator de diluição e, consequentemente, também dos níveis de $\mathrm{CO}$ medidos. Para simplificar a demonstração, serão realizados os cálculos somente para os valores de referência, admitindo-se que o CO esteja no seu VR correspondente.

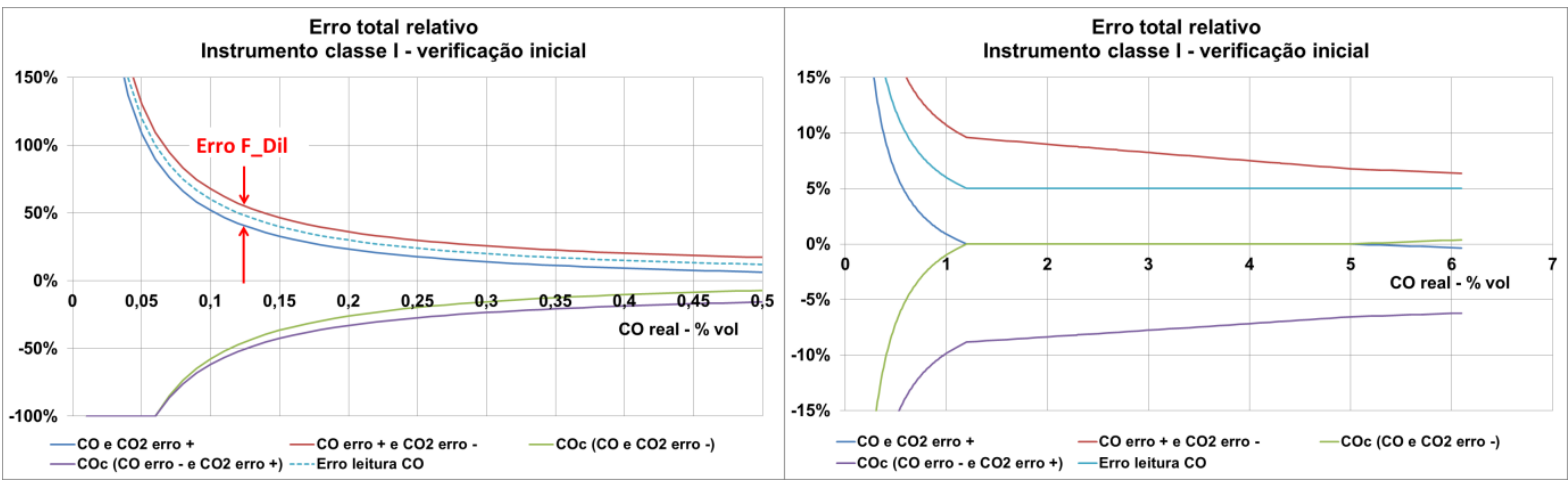

Nota: para melhor visualização, o gráfico da esquerda mostra apenas o início da escala do gráfico completo, à direita

Figura 5.2 - Erros máximos relativos de COc para equipamentos classe 0 e I

\subsection{Aplicação das tolerâncias no resultado da inspeção}

Para evitar reprovações indevidas, é necessário descontar da medição os erros máximos identificados no processo, a saber, o desvio máximo do analisador, a aderência efetiva de $\mathrm{HC}$ antes da medição e o erro introduzido no cálculo do fator de diluição decorrente dos desvios das medições de $\mathrm{CO}$ e $\mathrm{CO}_{2}$. $\mathrm{O}$ desconto da tolerância destes desvios aplicado à medição apresenta a vantagem de permitir que os VRs sejam definidos unicamente pelas características dos veículos e o Programa I/M não fique sujeito a tolerâncias desnecessárias quando for possível aprimorar os equipamentos e os procedimentos de medição.

Alternativamente, a empresa que realiza as inspeções poderá acrescentar os erros máximos, dos equipamentos que utiliza, aos VRs para determinar os seus próprios "valores de corte" (ou limites aceitáveis característicos do equipamento efetivamente utilizado), cujo efeito será o mesmo de descontá-los dos valores medidos. Apenas o valor da aderência de HC à sonda depende de modificação no sistema de medição, qual seja, a injeção de ar na sonda de amostragem em sentido contrário ao da coleta em todos os intervalos intra e inter-medições.

Recomenda-se, ainda, a adoção de recursos que minimizem os desvios mencionados, especialmente os decorrentes da evolução tecnológica dos equipamentos. Com os VRs propostos não terá mais sentido a utilização dos equipamentos analógicos e mesmo os de classe I, visto que a imprecisão e os erros de tais equipamentos são mais acentuados e incompatíveis com a verificação de veículos de baixa emissão, como será mostrado a seguir.

Para a avaliação do impacto dos erros admissíveis sobre os VRs propostos, foram calculados os erros que afetam a leitura de $\mathrm{CO}$ tanto diretamente como de forma indireta, através da incerteza sobre o fator de diluição, para equipamentos das classes 00,0 e I. A figura 5.3 ilustra a magnitude dos erros admissíveis nas medições de $\mathrm{CO}$ e $\mathrm{HC}$, em termos absolutos e relativos. 


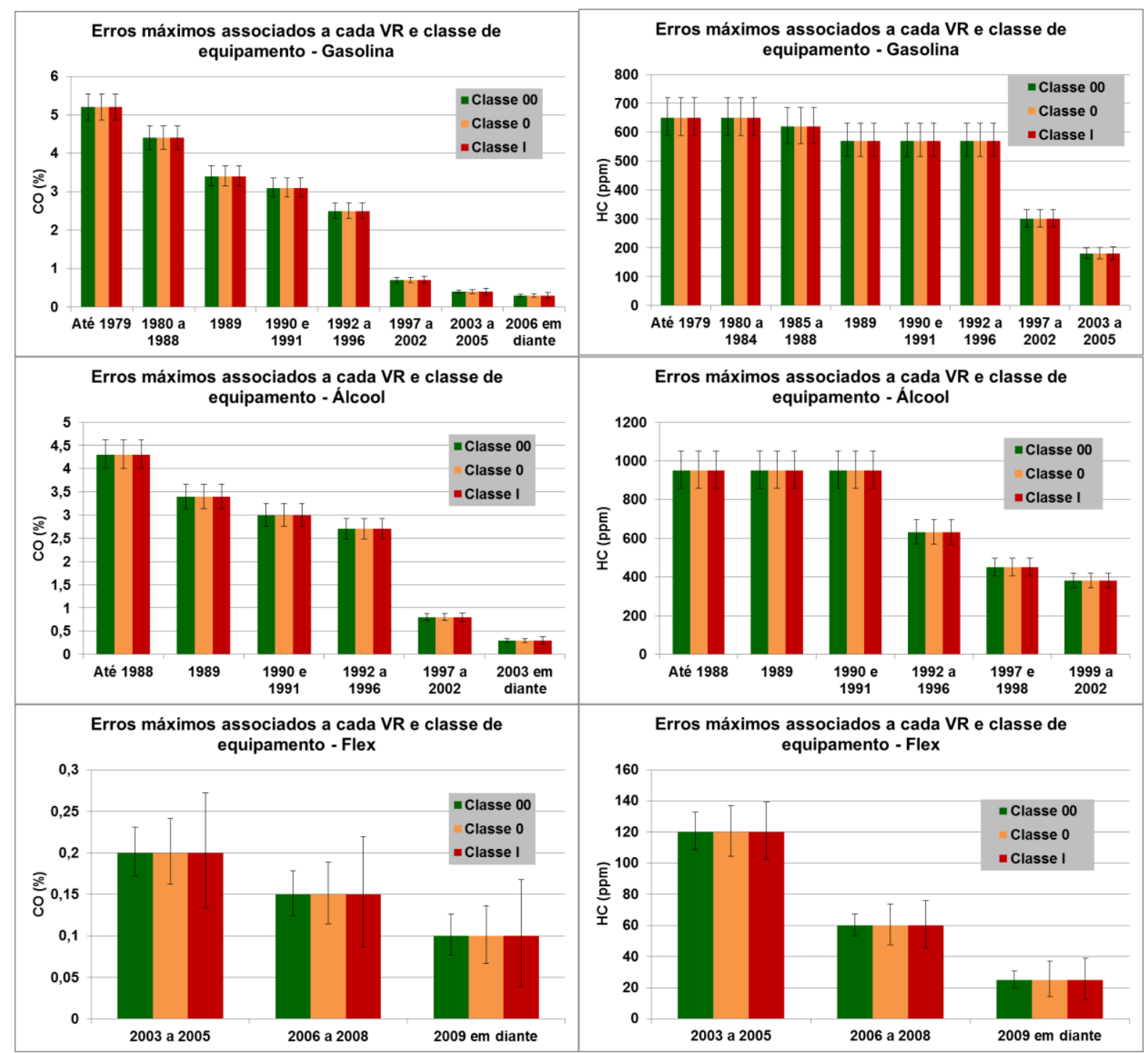

Figura 5.3 - Erros máximos admissíveis nas medições de COc e HCc

Os gráficos acima evidenciam a necessidade de revisão das tolerâncias permitidas no Brasil para a aplicação dos VRs propostos neste trabalho, sendo importante a utilização de equipamentos classe 0 e até mesmo recomendável a classe 00 , para os veículos fabricados a partir de 2006, especialmente para o aprimoramento das medições de CO. Por esta razão, a Portaria do Inmetro e as exigências do CONAMA devem ser revisadas em consonância com a norma OIML 99:2008, desaconselhando o uso de equipamentos classe I para a aferição de veículos posteriores a 2005 .

\section{CONCLUSÕES}

A análise dos percentis superiores das distribuições dos resultados do Programa I/M-SP permite avaliar a necessidade de revisões dos Valores de Referência (VRs) para a reprovação de veículos pelos seus níveis de emissão e uma determinação prévia de tais valores.

Foi constatado que os VRs atuais são lenientes em vários casos, sendo possível aumentar a eficácia do Programa I/M com limites inferiores aos atuais, entretanto, devem continuar em vigor para os dois primeiros anos após a implantação de novos Programas de Inspeção, pois 
todos os programas desse tipo devem ser implantados por etapas ${ }^{2}$, com ajustes graduais. Devemos observar que essa abordagem é para os programas que avaliam todos os veículos automotores com periodicidade anual a partir do primeiro ano de uso.

As propostas de novos VRs devem necessariamente ser confrontadas com os valores característicos de todos os modelos cotejando a viabilidade de atendimento e a eficácia do Programa I/M.

A revisão dos VRs para os Programas após o segundo ano de implantação é oportuna, e até necessária para a otimização do Programa I/M, devendo prever uma tabela de exceções para poucos modelos, quando necessário.

A validação das propostas deve ser feita a partir de uma simulação dos níveis de reprovação sobre os resultados obtidos no último exercício. Este estudo deve ser repetido periodicamente para a avaliação do aprendizado da sociedade acerca da correta manutenção dos veículos e a consequente estabilização dos resultados.

Diante dos VRs aqui demonstrados como viáveis, o Programa I/M não poderá ser operado com equipamentos analógicos, devendo utilizar equipamentos digitais classe 0 (zero) para os veículos mais novos. Além disso, as práticas de limpeza das sondas de amostragem com ar comprimido antes de cada inspeção são imprescindíveis.

Será necessário que o CONAMA estabeleça os novos VR juntamente com as tolerâncias máximas aceitáveis pelo Programa e exija o desconto da tolerância real das medições, sua determinação periódica e o controle de variabilidade de cada equipamento.

\section{REFERÊNCIAS}

${ }^{1}$ Instituto Brasileiro do Meio Ambiente e dos Recursos Naturais Renováveis - Programa de Controle da Poluição do ar por Veículos Automotores - PROCONVE/ PROMOT/IBAMA, 3 ed. - Brasília: IBAMA/DIQUA, 2011. 584 p. (Coleção Meio Ambiente. Série Diretrizes - Gestão Ambiental, n. ${ }^{\circ}$ 3)

${ }^{2}$ Branco, F.C.; Branco, G.M.; Szwarc, A.; Mello Filho, L. V. F. de; Napoleone, J. M. - Valores característicos dos parâmetros de referência de emissões dos veículos brasileiros - XXI SIMEA - 2013

${ }^{3}$ Branco, G.M.; Szwarc, A.; Branco, F.C. - Programa Ambiental de Inspeção e Manutenção Veicular Princípios, fundamentos e procedimentos de teste - São Paulo: Blucher, 2012

${ }^{4}$ USAID - U.S. Agency for International Development - Vehicle Inspection and Maintenance Programs: International Experience and Best Practices - A report for the Office of Energy and Information Technology, Washington, DC - October 2004

${ }^{5}$ Tabela de Empresas e Kits GNV com CAGN http://www.ibama.gov.br/index.php?option=com_phocadownload\&view=category\&download=187:p\&id=4\&Ite $\underline{\operatorname{mid}=331}$ - acesso em 15/05/2014 